\title{
Non-Operative Management of Type 2 ERCP-Related Retroperitoneal Duodenal Perforations: A 9-Year Experience From a Single Center
}

\author{
Vasileios Theopistos ${ }^{\mathrm{a}}$, Georgios Theocharis ${ }^{\mathrm{a}}$, Christos Konstantakis ${ }^{\mathrm{a}}$, Panagiotis Kitrou ${ }^{\mathrm{b}}$, \\ Ioannis Kehagias ${ }^{\mathrm{c}}$, Christos Triantos ${ }^{\mathrm{a}}$, Konstantinos Thomopoulos ${ }^{\mathrm{a}, \mathrm{d}}$
}

\begin{abstract}
Background: No consensus exists on treatment of endoscopic retrograde cholangiopancreatography (ERCP) -related, retroperitoneal duodenal perforations. The aim of this study is to determine the incidence of post-ERCP retroperitoneal periampullary (type 2) duodenal perforations and the clinical outcome of non-surgical management.
\end{abstract}

Methods: Patients who underwent ERCP in our institution during the period from January 1, 2009 to December 31, 2017 were included. Any cases of retroperitoneal periampullary duodenal (type 2) perforation were identified. Relevant data (patient characteristics, indications, radiographic findings, time to diagnosis and surgery, surgical procedures, hospital stay and outcome) were retrospectively collected and reviewed. Results were compared to those from the existing literature.

Results: There were 24 patients with retroperitoneal type 2 duodenal perforation following 4,196 ERCPs were identified (24/4196, 0.57\%) over the 9-year period. ERCP indications were: choledocholithiasis, obstructive jaundice and ampullectomy (ampullary adenoma). Diagnosis (aided by CT scan) was established within the first $12 \mathrm{~h}$ in the majority of patients $(21 / 24,87.5 \%)$ and intraprocedural in $3 / 24$, $(12.5 \%)$. Twelve patients $(50 \%)$ with deteriorating clinical course were managed with CT-guided percutaneous drainage. Surgical intervention was required in two $(8.3 \%)$. Overall mortality was $4.2 \%, 1 / 24$ (one patient died after surgery).

Conclusions: Retroperitoneal duodenal perforation is a rare and severe ERCP complication. However, conservative management is feasible in the majority of cases.

\section{Manuscript submitted March 20, 2018, accepted April 6, 2018}

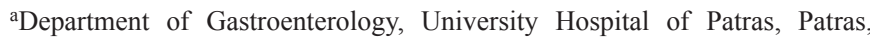
Greece

${ }^{b}$ Department of Diagnostic and Interventional Radiology, University Hospital of Patras, Patras, Greece

'Department of General Surgery, University Hospital of Patras, Patras, Greece ${ }^{\mathrm{d} C o r r e s p o n d i n g ~ A u t h o r: ~ K o n s t a n t i n o s ~ T h o m o p o u l o s, ~ D e p a r t m e n t ~ o f ~ G a s t r o-~}$ enterology, University Hospital of Patras, Patras, Greece.

Email: kxthomo@hotmail.com

doi: https://doi.org/10.14740/gr1007w
Keywords: Endoscopic retrograde cholangiopancreatography; Perforation; Iatrogenic; Endoscopy

\section{Introduction}

Although generally regarded as safe and despite recent technological advances as well as improvements in the experience and skill of endoscopists, endoscopic retrograde cholangiopancreatography (ERCP) remains a procedure with considerable complication rates that range from 5 to $12 \%[1,2]$. Duodenal perforation is the most severe and feared complication of ERCP with an incidence ranging from 0.4 to $1.6 \%$ [3-5]. Post-ERCP perforation carries a high mortality rate (4.5 to $33 \%)[3,4,6]$.

Post-ERCP perforations are grouped into four subtypes depending on the mechanism of injury and the anatomic location [7]. Type 1 perforations may occur to the lateral or medial duodenal wall, away from the ampulla of Vater, are usually caused by the shaft of the endoscope and they are typically large with extensive leakage into the intra and/or retroperitoneal space. Their management is well established, as it requires immediate surgery for the closure of the leak unless endoscopic sealing can be achieved during endoscopy [4].

Type 2 retroperitoneal perforations are perivaterian and occur during interventions in the periampullary area (as a result of sphincterotomy and/or balloon dilatation that extends beyond the intramural portion of the bile duct). They represent the most frequent type of perforation comprising 15 to $68 \%$ of all cases and their extent and severity are variable [7-9]. The optimal management of these injuries is not so well established. Although the term "perforation" causes anxiety in patients and even among health care workers who assume that it is an absolute indication for surgery, a non-surgical approach may be effective in these patients $[4,10]$.

Non-operative treatment is usually sufficient for types 3 (guidewire related bile duct perforation) and 4 (presence of retroperitoneal air alone probably due to minuscule ruptures and excessive air insufflation) as they usually close spontaneously and can be managed conservatively $[8,11,12]$.

We present a retrospective review of our experience with post-ERCP retroperitoneal type 2 perforations. The aim of 
this study was to determine the clinical outcome of non-surgical management and the efficacy of CT-guided percutaneous drainage usage in avoiding surgery even when septic complications arise.

\section{Materials and Methods}

All patients who underwent an ERCP during a 9-year period (from January 1, 2009 to December 31, 2017) were identified from an institutional database and all cases of post-ERCP perforation were retrospectively reviewed. These cases were then classified to the four types of perforations described in the introduction, depending on the underlying mechanism of injury (shaft penetration, endoscopic sphincterotomy, excessive balloon dilatation) and the anatomic location (proximal/ distal to the ampulla). Among them, data of patients with type 2 post-ERCP retroperitoneal periampullary duodenal perforations were analyzed. Patients with type 1, 3 and 4 perforations were excluded from this study as their management is well established. Retroperitoneal duodenal perforations were diagnosed by: 1) presence of free intra-abdominal air in an (oral contrast) abdominal CT-scan acquired upon clinical suspicion from symptomatic patients (abdominal pain, crepitus etc.) in the immediate post-ERCP setting; 2) detection of a luminal defect during the procedure (with or without contrast leakage). Upon diagnosis a multidisciplinary management approach was employed. The team involved in the decision making included the endoscopist/gastrointestinal specialist, a hepatobiliary surgeon and an interventional radiologist, and the patient was followed up closely. Concurrent post-ERCP bleeding and/or pancreatitis were not an exclusion criterion. All ERCPs were performed by three highly experienced endoscopists in a tertiary referral center.

The exact medical practice and the treatment plan that was followed for each patient was individualized and depended on factors like the time of diagnosis, the clinical course (improvement/deterioration) and the performance status of the patient. In cases of high intraprocedural suspicion of perforation an endoscopic closure of the leak with placement of endoclips or metal stent was attempted, when possible, even before the confirmation of diagnosis with a CT scan. All patients were initially treated with complete discontinuation of oral intake, analgesia as needed, intravenous fluids, broad-spectrum antibiotics, proton pump inhibitors and placement of a nasogastric tube for aspiration of gastric content and decompression. Patients' vital signs were regularly monitored and laboratory tests (on an as-needed basis) obtained. Total parenteral nutrition was initiated in malnourished patients or those who could not tolerate oral intake after a few days. In patients with continuing symptoms such as fever, constant abdominal pain, or persistent elevation of inflammatory markers in laboratory tests, despite optimal conservative management, a second CT scan was obtained. If any intra- or retroperitoneal fluid collections and abscesses were found, a CT-guided percutaneous drainage was performed. Operation was reserved for those with active leakage after oral contrast ingestion in the CT scan or the patients whose clinical status deteriorated and septic complications ap-
Table 1. Demographic and Clinical Characteristics of Patients With Type 2 Retroperitoneal Duodenal Perforation Following ERCP

\begin{tabular}{|c|c|}
\hline Characteristics & Value (\%) \\
\hline \multicolumn{2}{|l|}{ Age, year } \\
\hline Mean (SD) & $71.3 \pm 17.1(16.7)$ \\
\hline Range & $24-90$ \\
\hline Median & 71.1 \\
\hline \multicolumn{2}{|l|}{ Gender } \\
\hline Male & $10(41.7)$ \\
\hline Female & $14(58.3)$ \\
\hline \multicolumn{2}{|l|}{ ERCP indication } \\
\hline Obstructive jaundice & $3(12.5)$ \\
\hline Choledocholithiasis & $20(83.4)$ \\
\hline Ampullectomy & $1(4.1)$ \\
\hline \multicolumn{2}{|l|}{ Type of procedure } \\
\hline Guidewire-assisted sphincterotomy & $19(79.2)$ \\
\hline Needle-knife precut sphincterotomy & $3(12.5)$ \\
\hline Large balloon dilatation & $1(4.2)$ \\
\hline Ampullectomy & $1(4.2)$ \\
\hline
\end{tabular}

peared despite percutaneous drainage of fluid collections.

Demographic and clinical characteristics of the patients, indications for ERCP, radiographic findings, use of precut sphincterotomy, time to diagnosis and surgery, surgical procedures, hospital stay and outcome were recorded retrospectively.

\section{Results}

A total of 28 patients with duodenal perforation following 4,196 ERCPs were identified over the 9-year study period. Four patients with type 1 perforation were treated surgically and excluded from the study leaving 24 patients with type 2 perforation $(24 / 4196,0.57 \%)$. Fourteen were women and the mean age was $71.3 \pm 17.1$ (range: $24-90$ ). All patients had at least one concurrent disease.

Indications for performing an ERCP were known or suspected choledocholithiasis in $20(83.4 \%)$ patients, obstructive jaundice from a biliary stricture in three (12.5\%) and ampullectomy for ampullary adenoma in one patient. In four patients, a needle-knife precut sphincterotomy was performed and large balloon dilatation in one. Demographic and clinical characteristics of these patients are presented in Table 1.

Diagnosis was made within the first $12 \mathrm{~h}$ after ERCP completion in all patients. An intraprocedural diagnosis was possible in three (12.5\%) patients based on direct visualization of a luminal defect and the fluoroscopic presence of retroperitoneal (perirenal) air. An oral contrast abdominal CT scan was performed in all patients for the diagnosis and to exclude contrast leaking from the duodenum into the retroperitoneal space. Active leakage of oral contrast material was not noticed at any pa- 


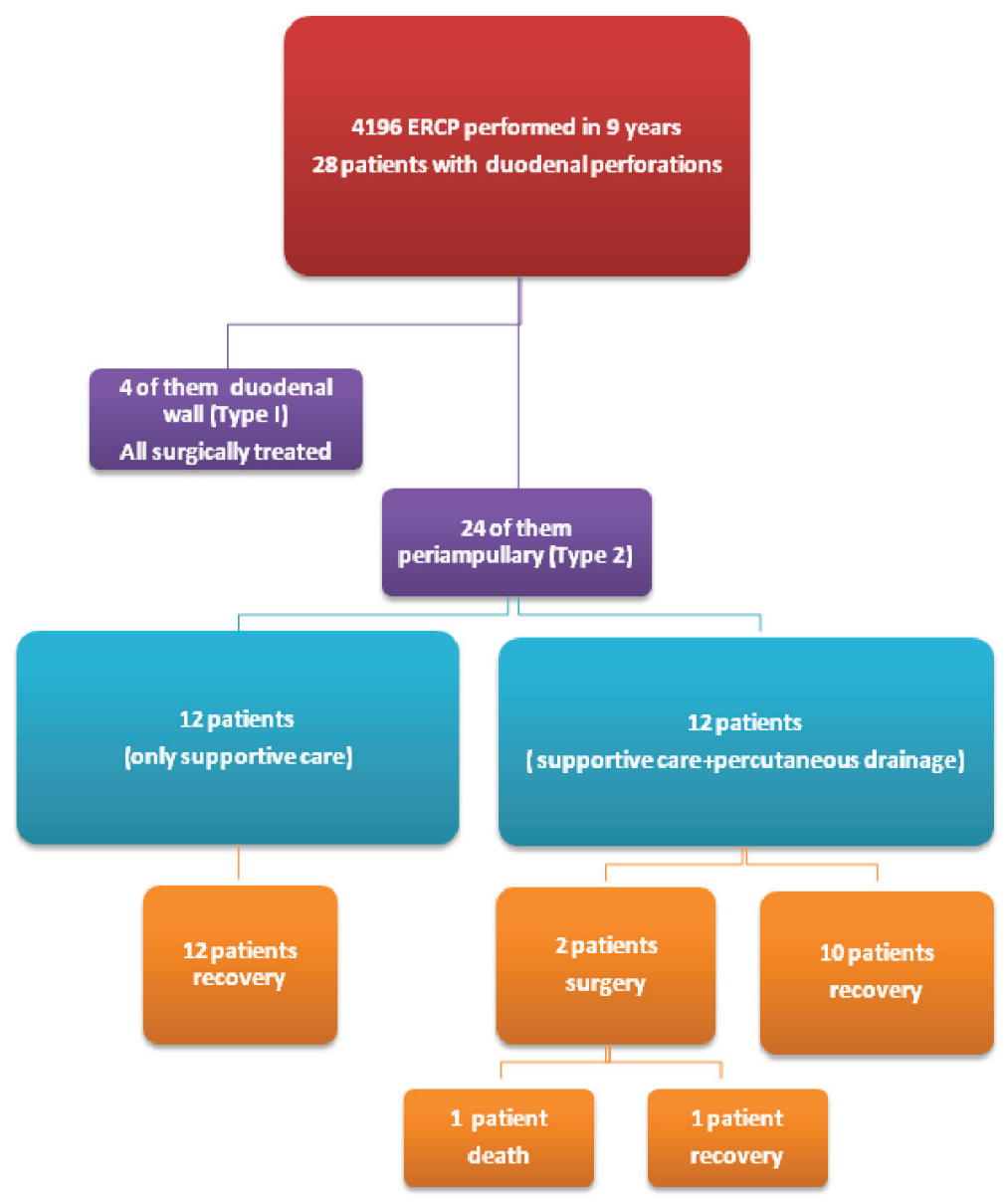

Figure 1. Flow-chart for clinical outcome of 24 patients with post-ERCP type 2 perforations.

tient. The pre-ERCP (endoscopic) plan was successfully completed in all but one patient and no procedures were interrupted due to perforation. In one case, the procedure was interrupted due to patient discomfort and repeated after 2 weeks for the clearance of the remaining bile duct stones. Figure 1 depicts clinical outcomes in our study group.

Endoscopic closure of the luminal defect was attempted on two separate occasions. The first case was treated with the placement of endoclips. The other patient was managed with the use of a fully covered self-expandable metal stent (FCSEMS) in order to achieve both adequate drainage of the bile duct and occlusion (by compression) of the leak site at the same time. Two (8.3\%) patients experienced immediate severe post-sphincterotomy bleeding; both were successfully treated with transarterial embolization.

Twelve (12) of the patients (50\%) showed worsening clinical symptoms of abdominal pain, fever and leukocytosis despite conservative treatment. A second CT scan was ordered on all these patients. It revealed retroperitoneal abscesses which were treated with CT-guided percutaneous drainage (Fig. 2). Drainage was successful in relieving the symptoms in 10 out of 12 patients $(83.3 \%)$. Two patients eventually required surgery $(2 / 24,8.3 \%)$. The first patient was operated upon 14 days after the perforation and after percutaneous drainage failed to control sepsis. The second patient 20 days post-ERCP and only after two CT-guided percutaneous drainage attempts did not succeed into reversing the clinical condition. Drainage and debridement of necrotic retroperitoneal tissue were surgically applied to both these patients.

Total parental nutrition because of prolonged fasting and malnutrition was given to four patients $(16.6 \%)$. Hospitalization time was $11.5 \pm 7.8$ days (range: 7 - 45 days).

One patient died (a patient with ischemic heart disease, about 1 month following surgery after suffering a cerebrovascular accident). The overall mortality amounts to $4.2 \%$.

A summary of the clinical outcomes of these patients is shown in Table 2.

\section{Discussion}

ERCP plays an important role in the treatment of pancreatobiliary diseases. However, ERCP patient population is often elderly with several other comorbidities. In this population death from all causes following the first ERCP reaches 5.0\% at 30 days from which only $0.09 \%$ is directly ERCP-related [13]. Duodenal perforation is one of post-ERCP complications with the highest mortality. Type 2 is the most common and 

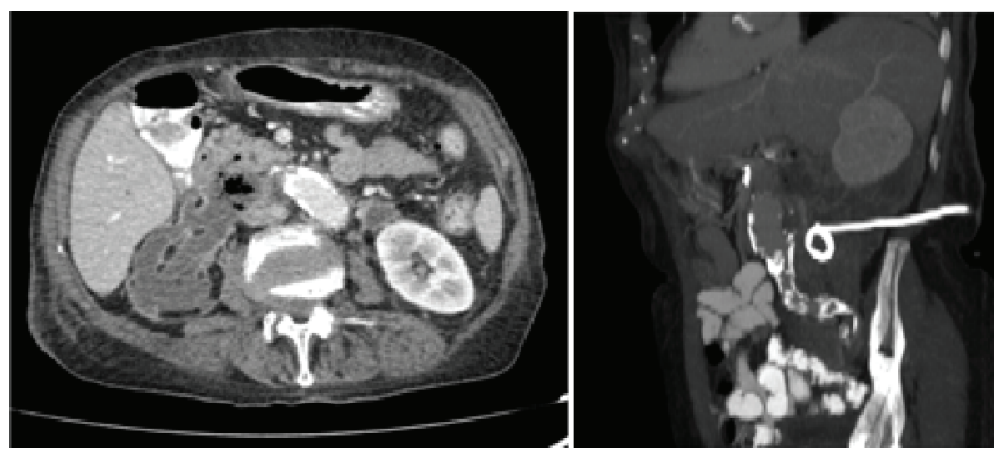

Figure 2. CT-scan showing the presence of free retroperitoneal air, fluid collections and the placement of a percutaneous drainage catheter.

its incidence appears to decrease in recent years, probably because of higher experience and skill of endoscopists performing ERCP $[6,14,15]$. Over a 9-year period in our department the incidence of type 2 post-ERCP duodenal perforations was low $(0.57 \%)$ as in most other studies with a low mortality rate $(4.2 \%)$.

Although most studies report an intraprocedural diagnosis of type 2 perforations ranging from $26 \%$ up to $100 \%$ [4, 16]; in our study this was only possible in $12.5 \%$ of the patients. One possible explanation is that in all cases the tear was small, as suggested by the complete absence of leakage of contrast in the retroperitoneal space in the CT scan. Early diagnosis is considered important as it makes endoscopic therapy feasible. It is based on careful observation of the duodenal wall near the sphincterotomy and the presence of air in the retroperitoneal space in fluoroscopy. On the other hand, all cases were diagnosed within the first $12 \mathrm{~h}$. It is our department policy to obtain a CT scan with oral contrast in all post-ERCP patients with abdominal pain not responsive to standard analgesics. There is no consensus in the literature of what is early or delayed diagnosis, but it is documented that early perforation recognition is associated with better prognosis [16-18]. In our study intraprocedural recognition of the perforation enabled immediate endoscopic treatment in two cases but did not affect the decision to refer for surgery as all patients were initially treated conservatively.

Endoscopic closure of the leak has been attempted with good results. Through the scope (TTS) clips have been successfully used, but their application is hard through a sideviewing endoscope, and there is a risk of clipping the ampulla $[19,20]$. Endoscopic placement of fully covered self- expandable metallic stents or/and nasobiliary drain insertion to close the leak and divert the bile duct flow away from the hole have also shown promising results [8, 21]. Both techniques were applied successfully, once each, in our series. However, in many cases perforation becomes evident after the withdrawal of the endoscope and all too often, even hours after the ERCP.

In the majority of cases the rupture closes spontaneously and no leakage is observed in subsequent examinations. In the absence of continuous leakage, adequate, broad-spectrum antibiotics might be sufficient to control the inflammation even if signs of systemic inflammation occur. In addition, radiologic interventions for percutaneous drainage of fluid collections make a non-surgical approach possible in these patients. There is increasing evidence that most type 2 retroperitoneal perforations could be managed without surgery [4, 17, 22, 23]. After careful patient selection conservative management is successful in more than $90 \%$ of patients [10]. In our series all 24 $(100 \%)$ were managed, at least initially, medically. Only two out of these 24 patients eventually required surgery at a later phase, after failure of conservative measures to control sepsis. The multidisciplinary approach utilizing CT-guided percutaneous drainage in the symptomatic patients with fluid collections $(12 / 24,50 \%)$ made recovery without the need for surgery possible in the $83.3 \%(10 / 12)$ of this difficult to treat group, even though no endoscopic treatment was offered in most of the cases. This could be due to the fact that periampullary perforations are small and early conservative treatment reduces the flow of gastric acid, bile and pancreatic secretions. Also, prompt use of percutaneous drainage reduces the risk of septic complications, which are responsible for most of the deaths reported in the literature.

High mortality rates of post-ERCP perforations reported in previous studies were not present in our series. Although by choosing conservative management for most patients, sur-

Table 2. Treatment Outcomes of Patients With Type 2 Retroperitoneal Duodenal Perforation Following ERCP

\begin{tabular}{lll}
\hline & $\begin{array}{l}\text { Conservative only treatment } \\
(\mathbf{n = 1 2 )}\end{array}$ & $\begin{array}{l}\text { Conservative only treatment }+ \text { CT-guided } \\
\text { percutaneous drainage }(\mathbf{n}=\mathbf{1 2})\end{array}$ \\
\hline Attempted endoscopic closure & 1 FCSEMS & 1 Endoclips \\
Hospitalization time & $10.0 \pm 2.4$ (range $7-14)$ days & $13.1 \pm 10.8$ (range $7-45)$ days \\
Total parental nutrition & 0 & $4(33.4 \%)$ \\
Surgery & 0 & $2(16.6 \%)$ \\
Death & 0 & $1(8.3 \%)$ \\
\hline
\end{tabular}


gery is reserved for those who do not respond to antibiotics and drainage, and are already septic and thus poor candidates for successful post-surgical recovery. Only one out of the two $(50 \%)$ patients referred for surgery died not as a result of failure to sufficiently control sepsis but due to other comorbidities. This finding is consistent with other reports $[4,11,16]$. Although mortality (4.2\%) in our study was low, it is notable that the non-surgical, conservative approach led to a prolonged hospital stay in most cases $11.5 \pm 7.8$ days (range: 7 - 45 days).

Our study has several limitations. First, it was retrospective and some post-ERCP type 2 duodenal perforations might not have been identified especially in patients treated in another hospital. Second, the study was performed at a tertiary center, with all recourses and medical specialties available. Surgical treatment might be preferable in centers with less experience in multidisciplinary management. Finally, because of the rarity of this complication the number of patients is small, although comparable with other single-center studies.

Retroperitoneal perivaterian duodenal perforations (type 2) are rare complications after ERCP with high morbidity and substantial mortality resulting in considerable medical and legal concerns for the endoscopist. Early diagnosis and treatment are essential to a better outcome. Endoscopic therapy could be instituted in all patients with intraprocedurally identified perforations [24, 25]. Post ERCP a high level of suspicion must be maintained for the early detection of this complication. An early oral-enhanced CT is the examination of choice in the appropriate clinical setting. Most post-procedurally detected type 2 perforations could be treated non-operatively initially. During nonsurgical management, a multidisciplinary team including endoscopists, interventional radiologists, and qualified surgeons, is recommended to determine the therapeutic plan (step-by-step) and indicate the necessity (if any)/timing of a possible surgical intervention. However, as there is substantial morbidity and mortality associated with surgery, this should be only reserved for the few who fail medical management.

\section{Conflict of Interest}

All authors declare that there is no conflict of interest.

\section{Author Contributions}

Vasileios Theopistos acquired and helped analyze the data and drafted the manuscript. Georgios Theocharis, Christos Konstantakis, Christos Triantos, Panagiotis Kitrou and Ioannis Kehagias contributed in the analysis and interpretation of data and critically revised the manuscript. Konstantinos Thomopoulos designed the study, helped in data acquisition and participated in drafting the article. All authors gave final approval to the version submitted.

\section{References}

1. Coelho-Prabhu N, Shah ND, Van Houten H, Kamath PS, Baron TH. Endoscopic retrograde cholangiopancreatog- raphy: utilisation and outcomes in a 10 -year populationbased cohort. BMJ Open. 2013;3(5).

2. Glomsaker T, Hoff G, Kvaloy JT, Soreide K, Aabakken L, Soreide JA, Norwegian Gastronet EG. Patterns and predictive factors of complications after endoscopic retrograde cholangiopancreatography. Br J Surg. 2013;100(3):373-380.

3. Miller R, Zbar A, Klein Y, Buyeviz V, Melzer E, Mosenkis BN, Mavor E. Perforations following endoscopic retrograde cholangiopancreatography: a single institution experience and surgical recommendations. Am J Surg. 2013;206(2):180-186.

4. Vezakis A, Fragulidis G, Polydorou A. Endoscopic retrograde cholangiopancreatography-related perforations: Diagnosis and management. World J Gastrointest Endosc. 2015;7(14):1135-1141.

5. Wu HM, Dixon E, May GR, Sutherland FR. Management of perforation after endoscopic retrograde cholangiopancreatography (ERCP): a population-based review. HPB (Oxford). 2006;8(5):393-399.

6. Andriulli A, Loperfido S, Napolitano G, Niro G, Valvano MR, Spirito F, Pilotto A, et al. Incidence rates of postERCP complications: a systematic survey of prospective studies. Am J Gastroenterol. 2007;102(8):1781-1788.

7. Stapfer M, Selby RR, Stain SC, Katkhouda N, Parekh D, Jabbour N, Garry D. Management of duodenal perforation after endoscopic retrograde cholangiopancreatography and sphincterotomy. Ann Surg. 2000;232(2):191198.

8. Polydorou A, Vezakis A, Fragulidis G, Katsarelias D, Vagianos C, Polymeneas G. A tailored approach to the management of perforations following endoscopic retrograde cholangiopancreatography and sphincterotomy. J Gastrointest Surg. 2011;15(12):2211-2217.

9. Enns R, Eloubeidi MA, Mergener K, Jowell PS, Branch MS, Pappas TM, Baillie J. ERCP-related perforations: risk factors and management. Endoscopy. 2002;34(4):293298.

10. Paspatis GA, Dumonceau JM, Barthet M, Meisner S, Repici A, Saunders BP, Vezakis A, et al. Diagnosis and management of iatrogenic endoscopic perforations: European Society of Gastrointestinal Endoscopy (ESGE) Position Statement. Endoscopy. 2014;46(8):693-711.

11. Machado NO. Management of duodenal perforation postendoscopic retrograde cholangiopancreatography. When and whom to operate and what factors determine the outcome? A review article. JOP. 2012;13(1):18-25.

12. Takano Y, Nagahama M, Yamamura E, Maruoka N, Takahashi H. Perforation of the papilla of vater in wire-guided cannulation. Can J Gastroenterol Hepatol. 2016;2016:5825230.

13. Kalaitzakis E. All-cause mortality after ERCP. Endoscopy. 2016;48(11):987-994.

14. Cotton PB, Lehman G, Vennes J, Geenen JE, Russell RC, Meyers WC, Liguory C, et al. Endoscopic sphincterotomy complications and their management: an attempt at consensus. Gastrointest Endosc. 1991;37(3):383-393.

15. Wang P, Li ZS, Liu F, Ren X, Lu NH, Fan ZN, Huang $\mathrm{Q}$, et al. Risk factors for ERCP-related complications: 
a prospective multicenter study. Am J Gastroenterol. 2009;104(1):31-40.

16. Jin YJ, Jeong S, Kim JH, Hwang JC, Yoo BM, Moon JH, Park SH, et al. Clinical course and proposed treatment strategy for ERCP-related duodenal perforation: a multicenter analysis. Endoscopy. 2013;45(10):806-812.

17. Kumbhari V, Sinha A, Reddy A, Afghani E, Cotsalas D, Patel YA, Storm AC, et al. Algorithm for the management of ERCP-related perforations. Gastrointest Endosc. 2016;83(5):934-943.

18. Li G, Chen Y, Zhou X, Lv N. Early management experience of perforation after ERCP. Gastroenterol Res Pract. 2012;2012:657418.

19. Baron TH, Gostout CJ, Herman L. Hemoclip repair of a sphincterotomy-induced duodenal perforation. Gastrointest Endosc. 2000;52(4):566-568.

20. Katsinelos P, Paroutoglou G, Papaziogas B, Beltsis A, Dimiropoulos S, Atmatzidis K. Treatment of a duodenal perforation secondary to an endoscopic sphincterotomy with clips. World J Gastroenterol. 2005;11(39):62326234.

21. Odemis B, Oztas E, Kuzu UB, Parlak E, Disibeyaz S, To- run S, Kayacetin E. Can a fully covered self-expandable metallic stent be used temporarily for the management of duodenal retroperitoneal perforation during ERCP as a part of conservative therapy? Surg Laparosc Endosc Percutan Tech. 2016;26(1):e9-e17.

22. Kodali S, Monkemuller K, Kim H, Ramesh J, Trevino J, Varadarajulu S, Wilcox CM. ERCP-related perforations in the new millennium: A large tertiary referral center 10-year experience. United European Gastroenterol J. 2015;3(1):25-30.

23. Fatima J, Baron TH, Topazian MD, Houghton SG, Iqbal CW, Ott BJ, Farley DR, et al. Pancreaticobiliary and duodenal perforations after periampullary endoscopic procedures: diagnosis and management. Arch Surg. 2007;142(5):448-454; discussion 454-445.

24. Park SM. Recent advanced endoscopic management of endoscopic retrograde cholangiopancreatography related duodenal perforations. Clin Endosc. 2016;49(4):376-382.

25. Verlaan T, Voermans RP, van Berge Henegouwen MI, Bemelman WA, Fockens P. Endoscopic closure of acute perforations of the GI tract: a systematic review of the literature. Gastrointest Endosc. 2015;82(4):618-628 e615. 